\title{
Corrigendum to "Enhanced Light Scattering by Preferred Orientation Control of Ga Doped ZnO Films Prepared through MOCVD"
}

\author{
Long Giang Bach,, Nam Giang Nguyen, ${ }^{2}$ Van Thi Thanh Ho, ${ }^{3}$ and Lu-Sheng Hong ${ }^{2}$ \\ ${ }^{1}$ NTT Institute of Hi-Technology, Nguyen Tat Thanh University, Ho Chi Minh City 70000, Vietnam \\ ${ }^{2}$ Thin Film Solar Cells Laboratory, Department of Chemical Engineering, National Taiwan University of Science and Technology \\ (NTUST), Taipei City 106, Taiwan \\ ${ }^{3}$ Ho Chi Minh City University of Natural Resources and Environment (HCMUNRE), Ho Chi Minh City 70000, Vietnam \\ Correspondence should be addressed to Van Thi Thanh Ho; httvan@hcmunre.edu.vn
}

Received 15 August 2016; Accepted 7 September 2016

Copyright ( 2016 Long Giang Bach et al. This is an open access article distributed under the Creative Commons Attribution License, which permits unrestricted use, distribution, and reproduction in any medium, provided the original work is properly cited.

In the article titled "Enhanced Light Scattering by Preferred Orientation Control of Ga Doped ZnO Films Prepared through MOCVD” [1], Dr. Lu-Sheng Hong was missing from the authors' list. The corrected authors' list is shown above.

\section{References}

[1] L. G. Bach, N. G. Nguyen, and V. T. Thanh Ho, "Enhanced light scattering by preferred orientation control of Ga doped ZnO films prepared through MOCVD,' International Journal of Photoenergy, vol. 2016, Article ID 1217576, 7 pages, 2016. 

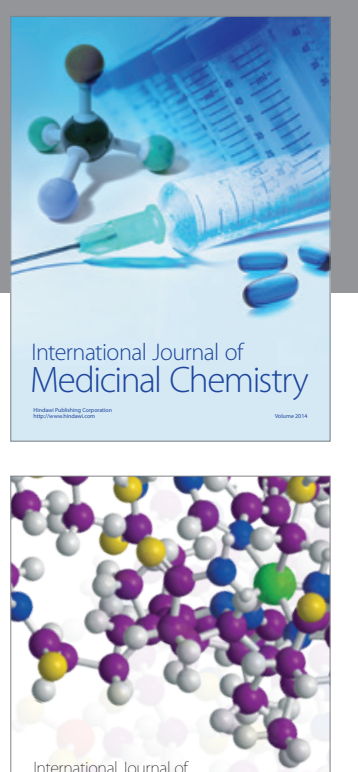

Carbohydrate Chemistry

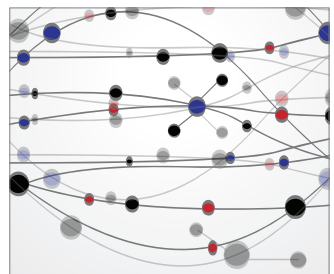

The Scientific World Journal
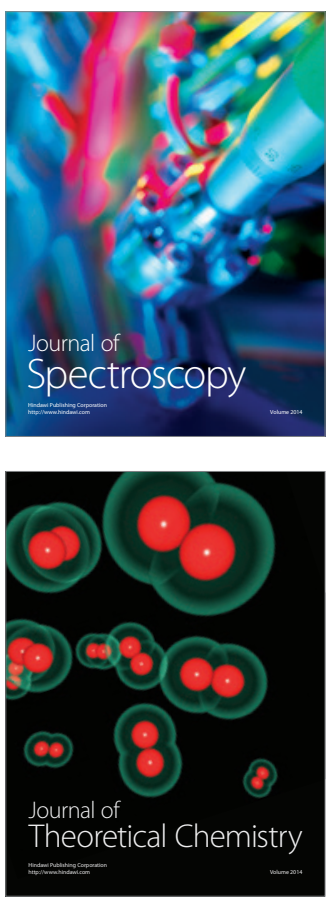
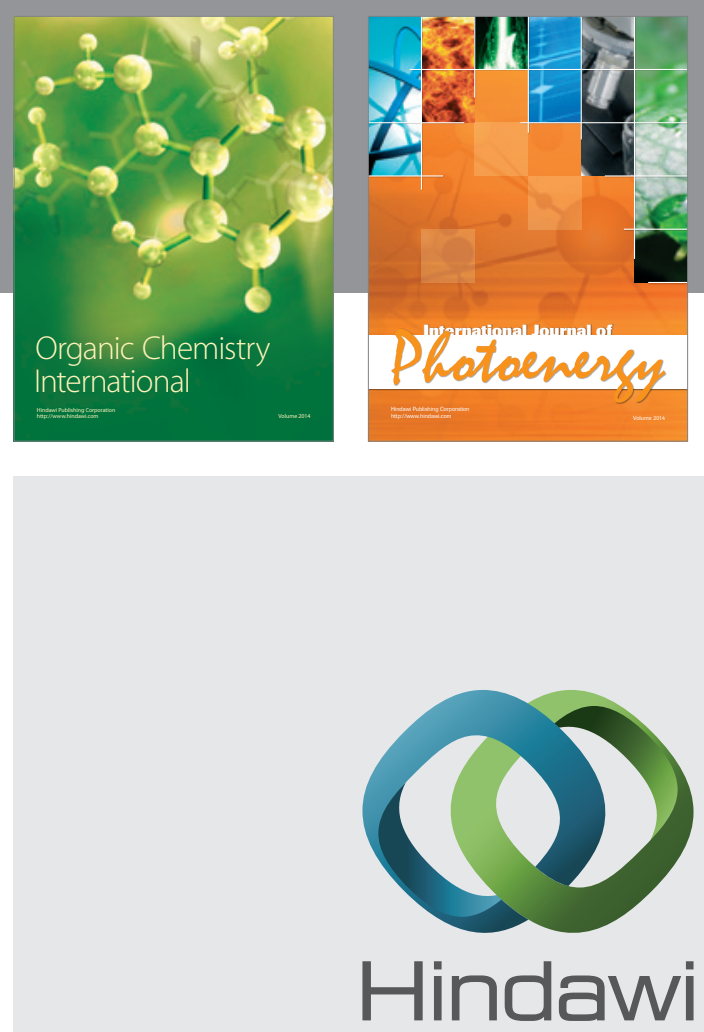

Submit your manuscripts at

http://www.hindawi.com

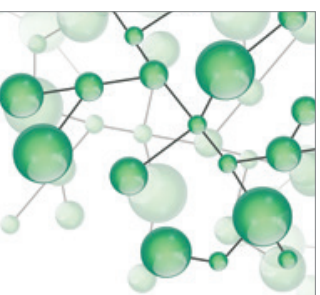

International Journal of

Inorganic Chemistry

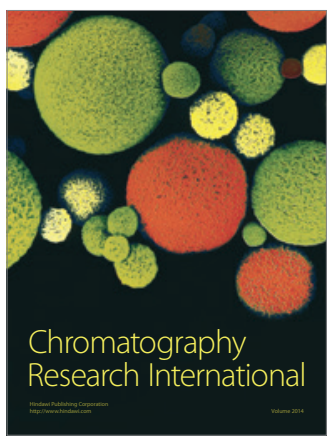

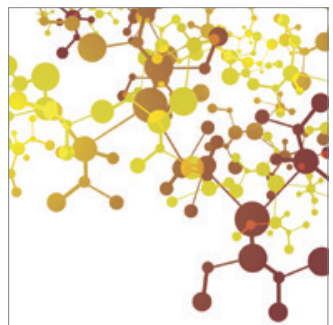

Applied Chemistry
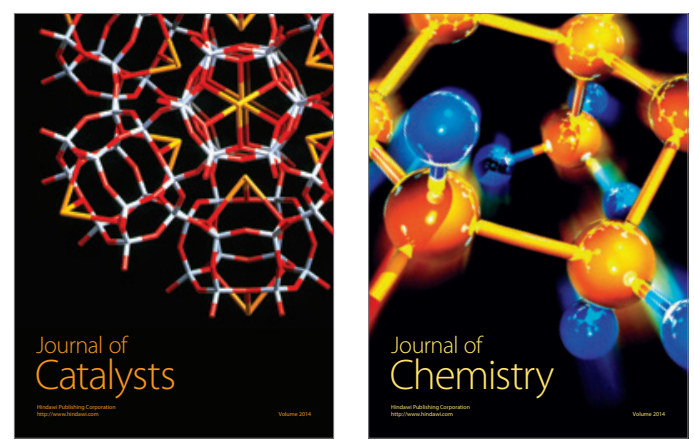
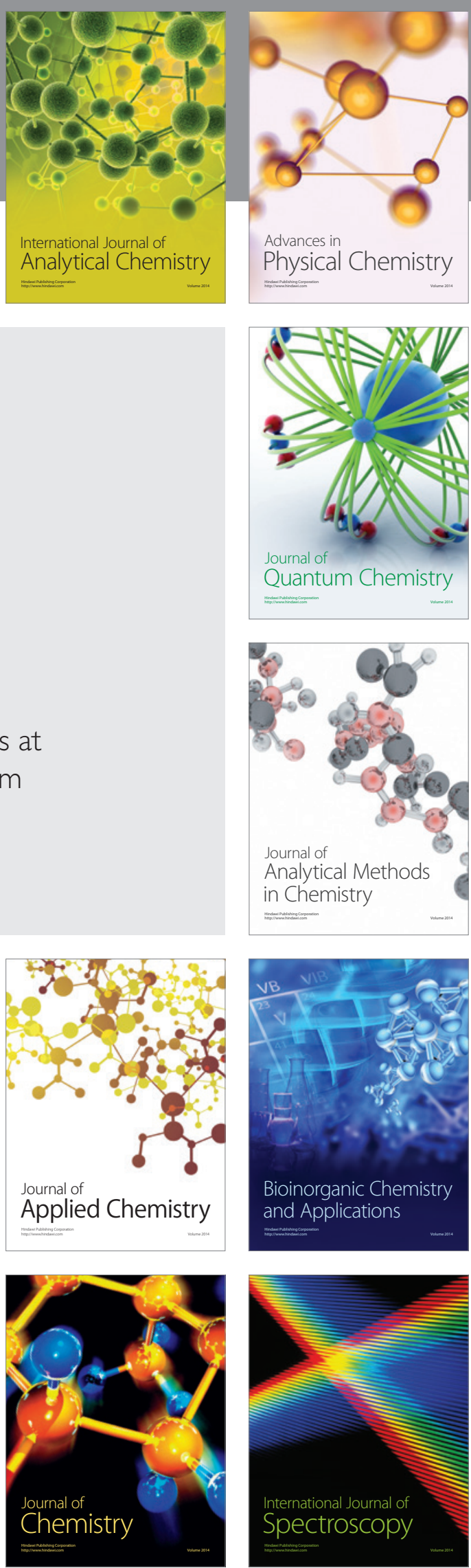